\title{
Smart city community governance system based on online and offline aggregation services
}

\author{
Xin Zhu ${ }^{1} \cdot$ Chunchun Chen ${ }^{1} \cdot$ Yunyao $\mathrm{Hu}^{2}$
}

Received: 10 March 2021 / Accepted: 17 August 2021 / Published online: 15 November 2021

○) Springer-Verlag GmbH Germany, part of Springer Nature 2021

\begin{abstract}
This paper takes smart city as an example, combining with online and offline aggregation services to explore the possible way out of county community governance innovation. In this white paper, community governance of online and offline aggregate services depends on the various assets and functions of the community, acts in collaboration with community stakeholders, and prevents and resists contingencies. Defined as a community with the ability to self-organize, self-adapt, and self-heal Interference or disaster to achieve sustainable development. This paper puts forward the benefit evaluation method of community governance, which is used to evaluate the implementation effect of online and offline community governance system. Taking a county as an example, this paper analyzes the impact of the challenge and novelty of this model on urban construction. Research shows that in the previous community governance model, about $50 \%$ of the people think that the managers of all institutions related to public welfare should not take management as the purpose, and even nearly $70 \%$ of the respondents also stressed that these institutions should not be allowed to collect legal management fees or commission fees. At the same time, $40 \%$ of respondents admitted that they did not trust the quality of free services provided by public welfare agencies. The online and offline aggregate service modes adopted by the city not only work well in the city's economy, but also increase the city's GDP by $12 \%$. This is $3.6 \%$ higher than in the previous mode. In addition, this model will accelerate the process of democratic construction and improve people's happiness index.
\end{abstract}

Keywords Online and offline aggregation services $\cdot$ Smart city $\cdot$ Community governance system $\cdot$ Big data technology

\section{Introduction}

In recent years, urban community governance has become the core content of social governance. How to build resilient communities and achieve effective urban governance with systematic thinking is a hot and difficult issue in the field of smart city research. Innovation ecosystem theory is an organic combination of innovation system theory and ecosystem theory, which emphasizes that all participants in the

Chunchun Chen

317791001@163.com

Xin Zhu

gltzhuxin@buu.edu.cn

Yunyao $\mathrm{Hu}$

1033731162@qq.com

1 School of Management, Beijing Union University, Beijing 100101, China

2 College of Economics and Management, Southwest Forestry University, Yunnan, Kunming 650224, China system cooperate with each other, complement each other in resources, create shared value, and realize the sustainable development of the system.

People from various industries have studied the community governance system of smart city from different perspectives. For example, moody $\mathrm{m}$ defines the community governance community as a collective community that is in a continuous stressful living environment but can self recover, self adjust and self learn from the perspective of online and offline aggregation services (Moody 2020). Markus ah believes that community governance community must have excellent management ability to deal with natural disaster events and other risk problems, and community governance can be improved through online and offline aggregation service planning, resource reserve, multi-party cooperation, psychological support, community leadership and death information feedback (Greenwood et al. 2008). Frumkin P believes that community governance has the ability to deal with interference and uncertainty, community resources are the core elements, and sustainable development is the 
long-term goal of community governance (Frumkin 2020). Letts $\mathrm{C} \mathrm{W}$ believes that the research on community governance in China started late and is still in the initial stage. At present, it is mainly applied to urban planning and disaster prevention and mitigation of online and offline aggregation services, which has not been well known by the management academia, and there is a certain gap in research depth with foreign counterparts (Letts et al. 2020). Jing y defines elastic community as a social community living in the same area or under the same risk, points out the community's initiative in disaster prevention and control, and advocates domestic scholars and relevant institutions to explore the localization of Community Governance (Jing and Gong 2020).

ONISHI T based on the performance of the grassroots community during the COVID-19, gave a detailed consideration to the community governance community construction in China's city (Onishi 2019). Zietsma C pointed out that community governance of online and offline aggregate services should have three characteristics: initiative, redundancy and agility. Community governance of community comes from four aspects: structural community governance, process community governance, ability community governance and cultural community governance (Zietsma and Lawrence 2020). In view of the systematic thinking of the theory, hsucl analyzes the current situation and development dilemma of the resilience construction of online and offline community aggregation services in China on the basis of combing the relevant literature of resilient community, and constructs the concept model of resilient community and the governance model of urban resilient community by using the innovation ecosystem theory, so as to provide theoretical reference for the community governance of smart cities in China (Hsu 2020). However, the communities and their governance status of more than 2000 county divisions across the country seem to be the shadow of the sun, and have not received the necessary attention (Spires 2018). Under the dual constraints of backward ideas and insufficient resources, counties in urgent need of institutional innovation are identified as followers who follow suit, that is, most of them take learning, imitating and learning from the experience of advanced regions at home and abroad as the main means to achieve the improvement of community governance within their jurisdiction (Durand et al. 2020). The above studies not only rarely involve the online and offline community governance of the third and fourth tier cities, but also fail to accurately grasp the new progress and direction of community governance at the county level.

This paper takes smart city as an example, combining with online and offline aggregation services to explore the possible way out of county community governance innovation. In the past, most literatures interpret government led smart city projects from the perspective of government purchasing services or public-private partnership. However, this form of project, which is based on venture capital, has its particularity. A general analysis from a government's point of view cannot help explore its unique policy values, nor can it analyze the difficulties and problems in its operation. At the same time, the lack of research status above further hampered more targeted improvement programs. From this point of view, this paper gradually introduces smart cities into the county community by using the cultural and cognitive perspective of organizational institutionalism as the main theoretical model and understanding and understanding new institutional forms and their practical behaviors. In particular, the specific process of transplanting specific institutional forms to new public policy scenarios and localizing them is called creative governance. It analyzes and sorts out how all parties change their views on key points in typical cases, and then develops new mechanisms.

\section{Community governance status and aggregation service model}

\subsection{Urban planning and community governance}

Community governance is introduced into urban planning, public management, organizational change and other fields of social science, which represents an agile resilience to external interference (Haveman 2020). Community governance, thinking theory and thinking method are also constantly integrated and developed into community governance thinking, which reflects the overall, regional, inclusive, innovative, systematic, diverse, humanized and dynamic characteristics of the system (Bies and Kennedy 2019). Scholars' research on community governance mostly focuses on individual psychological community governance, family community governance, organizational community governance, industrial community governance and industrial community governance, or community governance in five different dimensions of community, city, region, country and global (Battilana et al. 2020). It can be seen that although there are literatures at home and abroad on community governance from different perspectives, they all agree that community governance is a kind of ability to restore and maintain their own functions (Tracey et al. 2020). The early ideas of community construction and governance in the UK have made important contributions to the theory of community governance and community construction. In 2011, the UK incorporated community governance and community construction into the national strategic model (Sun et al. 2018). Community governance runs through the structure, process, ability and development level, not limited to disaster response and risk management (Wang et al. 2019).

From the perspective of community governance, the above situation has two possible advantages: first, due to 
the innovative requirements of smart city project, community leaders are forced to play the corresponding creativity, and no longer use traditional and rigid propaganda or mobilization means to solve some governance problems; second, in the face of the situation that the superior government is unwilling to transfer part of its functions to social organizations, the smart city, as a special form of government purchasing services, partly realizes the transfer of responsibilities and resources with the help of the community and its social organizations (Girardin et al. 2020). With the arrival of various administrative tasks, the community often plays an important role in personnel, funds and communication platform see elbow at the front (Gao et al. 2019). In fact, more and more community cadres have been found since 2018, and they are more responsible for government affairs (Zhou et al. 2017).

In other words, under the condition of ensuring the basic operation logic of smart city, embedding it into community governance has become a breakthrough for the further growth and development of the project (Chen et al. 2020). Finally, after two years of trial implementation of smart city, county a began to realize that the essence of smart city in county is to make up for the institutional defects of traditional government purchasing services, and gradually developed into a policy gripper to supplement community governance resources (Xu et al. 2018). Therefore, the function of smart cities is, to some extent, to restructure the basic conditions of communities and related social organizations, and is likely to be a possible way to achieve good social governance. It is more important than the adjustment of social contradictions (Wu et al. 2012). It is for this part of the project and this part of the tendency of these projects, funds or policies are relatively high, this year have been changed, I call social governance and charity smart city (Graf et al. 2019).

\subsection{China's smart city community governance and problems in governance practice}

Community governance community construction and governance theory China's community construction began in the early 1990s, has gone through the community construction experimental exploration stage and Community Construction Comprehensive deepening stage, now in the community governance stage (2010 to now). For a long time, China's grass-roots government has led the community construction and governance, the community lacks self-organization, and the community governance and community construction is in the ascendant (Shao et al. 2019). In 2011, the international agency for disaster reduction (ISDR) launched a global campaign for community governance City, and Chengdu became the first internationally recognized community governance city in China with its excellent experience in post earthquake rescue and post disaster reconstruction (Xing et al. 2020).

(1) The corresponding financial policy support is insufficient

This paper proposes an online and offline aggregation service association model to solve the problem of error in governance practice

$\mathrm{W}\left(y, y^{\prime}\right)=\frac{\sum_{i=1}^{m}\left(y_{i}-y_{i}^{\prime}\right)}{m}$

where $\mathrm{W}$ is the deviation gap, $\mathrm{M}$ is the interval year, and $\mathrm{Y}$ is the average error. The evaluation parameters are as follows, where $p$ represents the improvement of urban economy rate:

$f(x)=\sum_{j \subset Q} c_{j} \frac{x_{j}}{\sigma\left(X_{j}^{\prime}\right)}-p$

$P\left(d_{i}, w_{j}\right)=P\left(d_{i}\right) P\left(w_{j} \mid d_{i}\right) ; P\left(w_{j} \mid d_{i}\right)=\sum_{k=1}^{K} P\left(w_{j} \mid z_{k}\right) P\left(z_{k} \mid d_{i}\right)$

$D B I=\frac{1}{k} \sum_{i=1}^{k} \max _{j: i}\left\{\frac{D \text { intra }(C i)+D \text { int } r a(C j)}{\operatorname{Dinter}(C i, C j)}\right\}$

It can be seen that compared with the practice of western countries, China's smart city activities have their own characteristics and expertise, that is, most smart cities in cities mainly rely on the form of government projects to promote, and the core work is related to the ability cultivation of social organizations and the effective promotion of social innovation.

(2) Governance scenarios and the promotion of smart city restrict each other

But more importantly, many social organizations, especially those called grassroots organizations, are difficult because they lack the necessary social foundations and legitimacy and are difficult to integrate into their communities Acquiring survival resources to sustain their long-term development.

\subsection{Community governance model of smart city based on online and offline aggregation services}

The model includes two aspects: first, the theoretical logic model, including the goal and task, system composition, relationship structure, innovation process and implementation method of the whole governance model. Second, 
hard infrastructure and modern scientific and technological means in practice. Based on the above four elements, this paper proposes an urban community governance model based on innovation ecosystem

$\wp_{\kappa}=\frac{2 k}{k+1}+\left[\frac{1}{2}+\frac{1}{2 k}\right]\left[\frac{c_{2}-c_{1}}{3}\right]^{2}+\frac{2\left(c_{2}-c_{1}\right)}{3}$

$\psi=\sum_{x=1}^{\theta} V x=\sum_{x=1}^{\vartheta}\left(\frac{W x}{\sum_{1}^{n} W_{\mathfrak{I}}} S x\right)$

In the above formula, $\mathrm{K}$ is the scale of the city, $\mathrm{C}$ is the degree of construction. This model comprehensively considers the whole city system, including four subsystems, as shown in Fig. 1, which shows the government service system, community autonomy system, auxiliary governance system and information exchange system.

Therefore, the function of system 1 is to provide strict system guarantee service, simple and efficient administrative service and complete public infrastructure construction service for the whole community governance.

System 2 consists of several sub community autonomous systems composed of residents, families, communities and community committees. Community members rely on themselves and various capitals of the community to handle community affairs.

System 3 is composed of institutions of higher learning, citizen organizations, enterprises and other professional institutions, which plays an auxiliary role in community governance.

System 4 is the intelligent integration of "Internet plus" and community governance. The service government realizes the information interaction and feedback of various systems through hi-tech information technology, so as to timely release the upper level requirements or get the basic level appeal, so as to improve the community management community operation, save manpower cost and improve service efficiency, among which $\mathrm{C}$ is the value cost, Sd represents the conversion relationship of cost and the cost is improved. The relationship is as follows:

$S d_{\text {gain }}(Y)=\frac{\sigma(Y)-\operatorname{avg}\left(\sigma\left(Y^{\prime}\right), \sigma\left(Y^{\prime}\right)\right)}{\sigma(Y)}$

$\mathrm{C}(\mathrm{k})=\left[\zeta_{1} \mathrm{c}_{1}(\mathrm{t})+\zeta_{2} \mathrm{c}_{2}(\mathrm{k})+\zeta_{3} \mathrm{c}_{3}(\mathrm{k})+\zeta_{4} \mathrm{c}_{4}(\mathrm{k})+\zeta_{5} \mathrm{c}_{5}(\mathrm{k})+\zeta_{6} \mathrm{w}_{\mathrm{ik}}\right]$

$c_{1}(t) \geq 0, c_{2}(k) \geq 0, c_{3}(k) \geq 0, c_{4}(k) \geq 0, c_{5}(k) \geq 0$

\subsection{Benefit evaluation method of community governance}

The governance model constructed in this paper is guided by urban governance, which requires the joint efforts of all innovative governance subjects in the four subsystems to jointly promote the transformation of the whole city's grassroots social governance
Fig. 1 Schematic diagram of smart city community governance system (Images retrieved from Google, none of the images have copyright requirements)

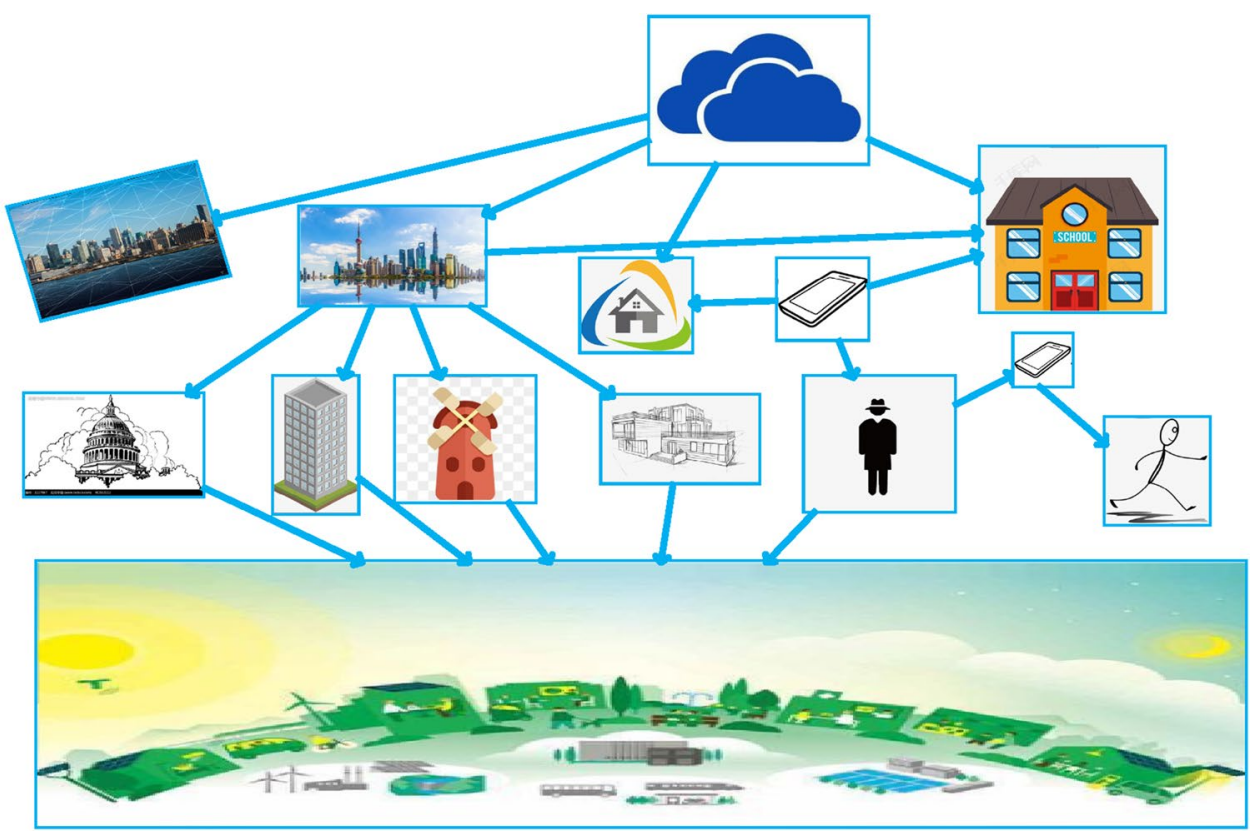


$\min w_{k}(t)=\left[\omega_{1}\left(\frac{d_{k}}{V}\right)+\omega_{2}\left(\frac{d_{k}}{V}\right)+\omega_{3}\left(\frac{T_{k}}{N D_{K}}\right)+\omega_{1}\left(P_{K} T_{K}\right)\right]$

$\vartheta=\frac{2 k}{k+1}+\frac{2 c_{1}+c_{2}+3 e t-2 e t \zeta}{3}$

Community governance community construction and governance theory the rudiment of community governance community construction theory originated from Britain.

\section{Experimental design and research process}

\subsection{Research content}

This paper defines community governance of online and offline aggregate services as a community that relies on various assets and capabilities of the community, acts together with community stakeholders, and has the ability of selforganization, self adaptation and self recovery to prevent and resist accidental interference or disasters, so as to achieve sustainable development. This paper puts forward the benefit evaluation method of community governance, which is used to evaluate the implementation effect of online and offline community governance system. Taking a county as an example, this paper analyzes the impact of the challenge and novelty of this model on urban construction.

\subsection{Experimental design and data collection}

Considering that most of the existing literatures focus on the innovation and achievements of community governance in the first and second tier cities, the empirical analysis at the county level still needs to be strengthened. Therefore, this paper selects a typical county-level city-county a (pseudonym) and its corresponding (city) community practice as a case study for analysis, and mainly adopts qualitative data to carry out the corresponding research. The core of the case study method is to find and describe the outliers (cases) excluded in the traditional quantitative analysis.

The case-based research method is applicable to the basic problems of this paper. At the same time, the challenge and novelty of this paper make it necessary to grasp and sort out the practical materials in an exploratory way, rather than simply using the original statistical data or questionnaire survey to outline and explain. The case involved in this paper is county a in our city, which is a typical county in eastern China. The county covers an area of more than 1400 square kilometers, has a permanent resident population of more than 600,000 , and the per capita GDP in 2018 is 96,000 yuan, which is a relatively rich area in general. Like the traditional county-level cities in China, a county is facing certain transformation difficulties and problems in the context of rapid economic development, and the realization of urban community benign governance has become its important governance goal. Among them, the smart city of the county is mainly led by the Party committee, funded by a number of government departments, and entrusted to the county community, the largest local 5A level social organization, to implement and realize.

(1) Construct the concept model of community governance of online and offline aggregation service community

The establishment of a conceptual model of community governance is helpful for community stakeholders to intuitively understand the influencing factors, formation process, governance objectives and governance contents of community governance. Based on the research results of domestic and foreign scholars on the connotation of community governance, combined with the recent research results of innovation ecosystem, from the perspective of process, this paper constructs the conceptual model of community governance of online and offline aggregation service community. The conceptual model can explain the differences of community governance level in different communities, and also point out the intervention direction for improving the community governance level.

(2) Building a new model of urban community governance with online and offline aggregation services

Community governance based on innovation ecosystem needs to pay attention to the basic elements of the system, namely: principles, participants, contents and models. Starting from these four basic elements, this paper first expounds the new ideas of urban community governance, and then puts forward a new governance model. Establish a full cycle community governance mechanism covering early warning, triggering, emergency, recovery and change, and promote the flexible connection between the public emergency management system and the basic community governance system. In addition, we should promote multiple subjects to participate in community governance. Community governance all parties involved in the construction of community should innovate community governance ways and methods, in particular, we need to give play to the spirit of community residents as masters, mobilize their governance initiative, stimulate the third-party auxiliary construction role of universities, citizen organizations, enterprises and other professional institutions, and give full play to the complementary advantages of resources to alleviate the phenomenon of excessive government arrangement and market failure. 


\section{Results and discussion}

\subsection{Smart city community governance system based on online and offline aggregation services}

As shown in Fig. 2, when the smart city is introduced into China, its main investors turn into local government departments rather than foundations and other entities, and constitute a "variant" of local government purchasing services. This trend has been paid attention to and discussed in the existing literature. However, the existing relevant studies either focus on the analysis and carding of smart city cases in big cities, or focus on the description of the process of smart city diffusion, and fail to grasp the role transformation of this institutional form when it spreads to the county level and the local governance implications of the corresponding functional changes. In order to better understand how this specific institutional form and its practice spread to the county-level region and finally integrated into local governance.
As shown in Fig. 3, the construction of smart city is multifaceted. Community planning should break through the thinking limit of project community governance, act as a media role, stimulate the participation of community residents and assist the community to build a social network system. Community governance covers both physical space and social space. With the downward shift of government emergency management to grassroots social governance, communities need to make full use of modern information technology model to expand governance space, manage physical space and social space in a two pronged way, improve community science and technology community governance, and build "social governance community", adhere to the principle of practice orientation. Community governance community construction is not on paper, it must be able to implement, the social parties involved in the construction should build and share value, create together, interact with the external environment to form an innovative ecological whole, and then realize innovative governance.

As shown in Table 1, the existing research focuses on how the new institutional form of smart city and its corresponding practice are gradually formed in one place and spread to other regions: for example, moody starting from
Fig. 2 The process of investment entities' proliferation of smart cities
Fig. 3 Differences in the construction of smart cities
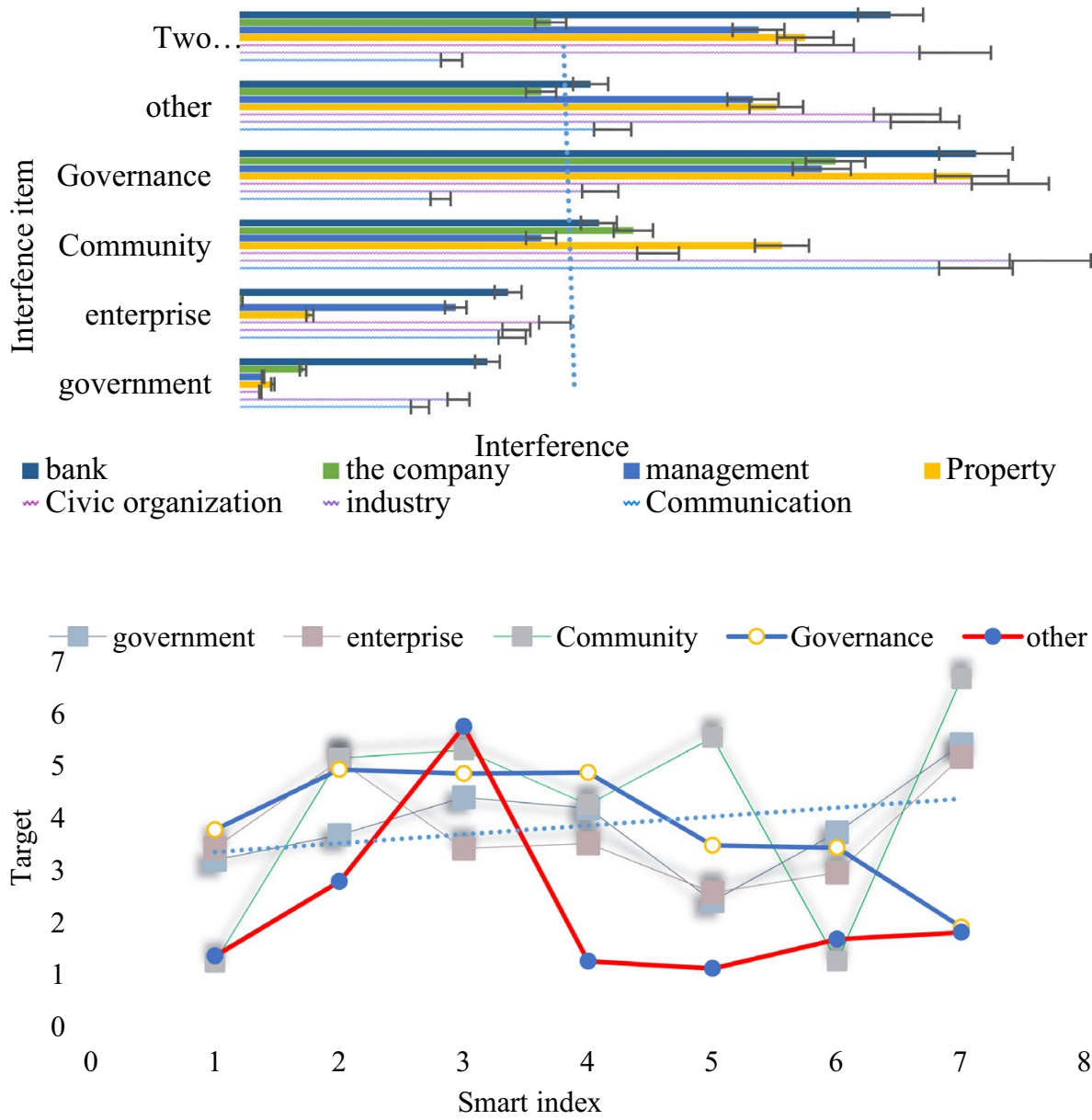
Table 1 Institutions' investment in online and offline governance models

\begin{tabular}{llllll}
\hline Item & Communication & Industry & $\begin{array}{l}\text { Civic organi- } \\
\text { zation }\end{array}$ & Property & Management \\
\hline Government & 1.31 & 1.59 & 0.15 & 0.24 & 0.17 \\
Enterprise & 1.98 & 2.01 & 2.29 & 0.51 & 1.57 \\
Community & 5.35 & 5.89 & 3.04 & 3.94 & 2.19 \\
Governance & 1.46 & 2.62 & 5.6 & 5.32 & 4.23 \\
Other & 2.71 & 4.98 & 4.85 & 3.9 & 3.73 \\
Two committees & 1.54 & 5.2 & 4.25 & 4.11 & 3.77 \\
\hline
\end{tabular}

Fig. 4 Managers' treatment of public welfare-related institutions
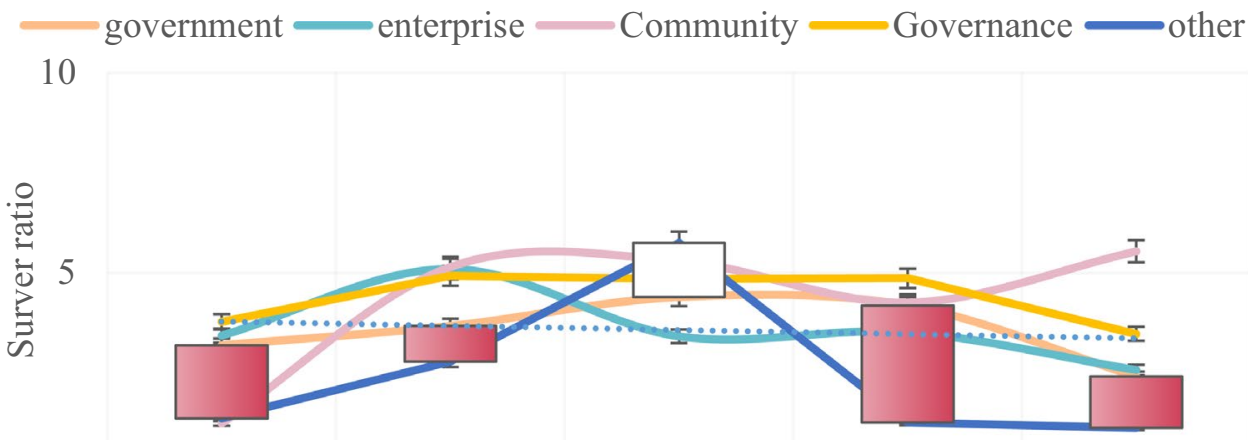

0

2016
2020
Years 2018 the formation of professional culture and the change of identity of major participants, this paper systematically studies how the field of smart city in the United States gradually came into being and emerged with the help of the analysis model of "organizational isomorphism" of new institutionalism, and discusses how the core concepts in this field, such as effectiveness, accountability and measurability, derived from the commercial field, are transferred to the non-profit department door has gradually become the basic content of smart city.

As shown in Fig. 4, in the previous community governance model, about $50 \%$ of the respondents thought that the managers of all institutions related to public welfare should not take management as the purpose, and even nearly $70 \%$ of the respondents stressed that these institutions should not be allowed to collect legal management fees or commission fees. At the same time, $40 \%$ of respondents admitted that they did not trust the quality of free services provided by public welfare agencies. The online and offline aggregation service mode adopted by a not only performs well in the city's economy, but also increases the city's GDP by $12 \%$, which is $3.6 \%$ higher than the previous mode. In addition, this model will accelerate the process of democratic construction and improve people's happiness index.

As shown in Table 2, social organizations are not only unable to serve the public, but also lack the necessary resources to maintain themselves. It can be seen that
Table 2 Public service of social organization

\begin{tabular}{clllll}
\hline Years & Government & Enterprise & Community & Governance & Other \\
\hline 2016 & 3.2 & 3.44 & 1.25 & 3.78 & 1.37 \\
2017 & 3.68 & 5.1 & 5.15 & 4.93 & 2.79 \\
2018 & 4.4 & 3.42 & 5.3 & 4.85 & 5.75 \\
2019 & 4.19 & 3.52 & 4.26 & 4.87 & 1.27 \\
2020 & 2.42 & 2.58 & 5.54 & 3.48 & 1.13 \\
\hline
\end{tabular}

people's understanding of social organizations has its traditional side, that is, they recognize the simple concept of "good people and good deeds". At the same time, people have the "economic man" side of modern citizens or consumers, which emphasizes the market pricing of public services, and thinks that "cheap goods are not good goods". In depth investigation will find that another important structural reason for this situation is that as of June 2014, there are more than 1600 legally registered social organizations in our city, but the vast majority are mutual beneficial industry associations or social organizations, which are only limited to the activities related to internal members, and there are not many influential public welfare social organizations that are really oriented to the general public. It is difficult for the local civil affairs department to find a recognized representative organization. 
Table 3 Various government purchase service items

\begin{tabular}{llllll}
\hline Item & Government & Enterprise & Community & Governance & Other \\
\hline Communication & 3.2 & 3.44 & 1.25 & 3.78 & 1.37 \\
Industry & 3.68 & 5.1 & 5.15 & 4.93 & 2.79 \\
Civic organization & 4.4 & 3.42 & 5.3 & 4.85 & 5.75 \\
Property & 4.19 & 3.52 & 4.26 & 4.87 & 1.27 \\
Management & 2.42 & 2.58 & 5.54 & 3.48 & 1.13 \\
Bank & 5.41 & 5.17 & 6.66 & 1.92 & 1.82 \\
\hline
\end{tabular}

As shown in Table 3, although various government purchase service projects have been written into the work of many county governments in our city, few of them are actually implemented in actual operation. According to the introduction of local officials, due to the strict standards of government purchase service process, few local social organizations can meet the requirements. Not only is the government concerned about this aspect of work even the leaders of various social organizations have little confidence in whether their organizations can undertake government tasks.

As shown in Fig. 5, vehicle identification in smart city governance is also an important branch. People can not effectively contact with social organizations in community life. They only judge social organizations and their attributes by their vague impression of "smart city". The situation where many mutually beneficial social organizations are "entertaining themselves" leads to "great disappointment" with people's possible functions and functions. Furthermore, different from the high recognition and understanding of the main functions of multiple social governance by large-scale city governments, from the perspective of county-level governments, whether social organizations, especially grass-roots organizations, have the ability to undertake services purchased by the government, or even undertake part of the governance functions, not only has a lot of insurmountable obstacles in concept, but also has no practical significance corresponding breakthrough.

As shown in Fig. 6, the popularity of the system form of smart city and its corresponding practice in China will also show a certain "global localization" characteristics, that is to say, it not only reflects the basic attributes of smart city itself, but also can be accepted and applied by the implementers in the introduced regions. Similar situations often occur in China's social organizations and charity fields. Specifically, the practice of emerging content such as smart city in China is the product of the global spread of "new frontier of public welfare", which is essentially reflected in the process of audience imitation, learning and transformation in the receiving country. So many scholars analyze the conditions and basis of similar practice in China from the perspective of institutional premise and resource allocation of smart city in western society.

The analysis results show that the consistency between external institutional logic and internal identity of the organization will affect the access of social organizations to smart city funds. Therefore, the "leverage" role of smart city in reality is different. The research on institutional diffusion in China shows that different levels of local governments can achieve their own policy objectives by adopting different ways of smart city. As shown in Table 4.

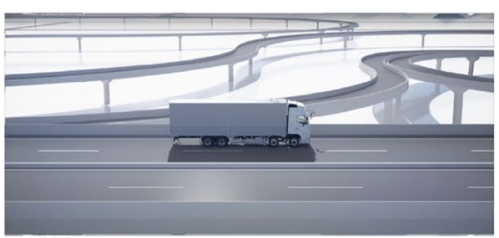

(a)

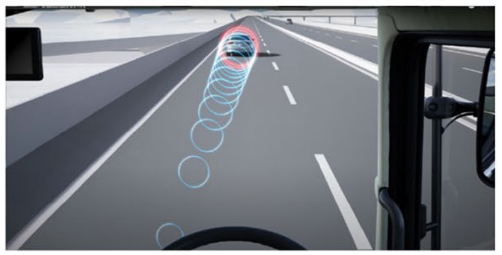

(d)

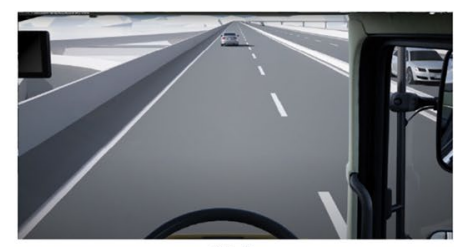

(b)

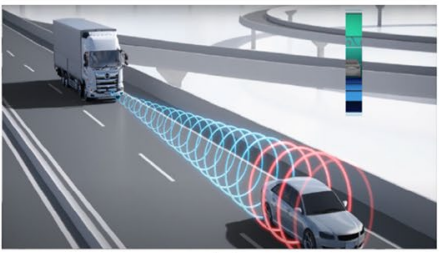

(e)

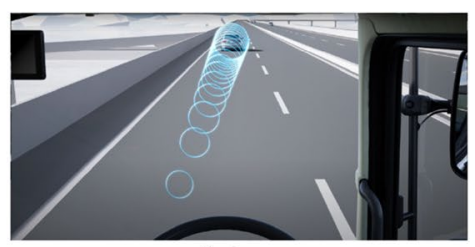

(c)

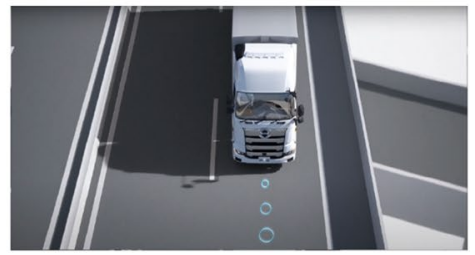

(f)

Fig. 5 Vehicle identification in smart city governance (From Google: https://www.youtube.com/watch?v=6bGrxkg94j0) 
Fig. 6 Basic attributes of smart city itself (The pictures are all from Google, all pictures have no copyright requirements)

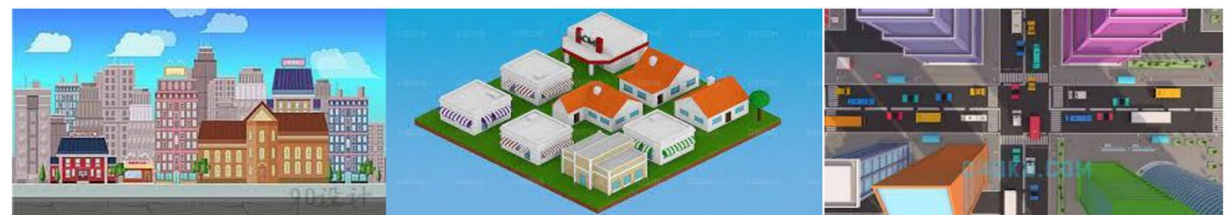

(a)

(b)

(c)

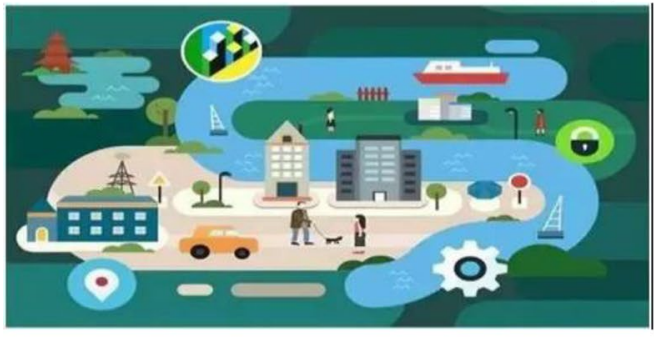

(d)

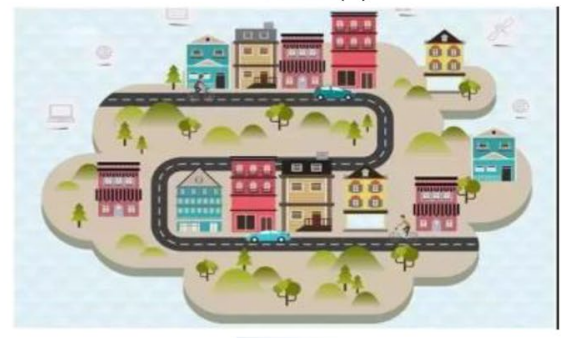

(e)

Table 4 Main indicators of Smart City Index

\begin{tabular}{lll}
\hline Dimension & Working area & Indicator \\
\hline Environment & Smart buildings & Sustainability-certified buildings \\
& Resources management & Smart homes \\
& Energy \\
& Carbon footprint \\
& Air quality \\
& Waste generation \\
& Water consumption \\
& Climate resilience planning \\
& Density \\
& Green space per capita \\
\hline
\end{tabular}

(The data source of the survey comes from: Smart City Index Master Indicators Survey, the annual ranking of popular smart cities conducted by the council consultant Boyd Cohen)

As shown in Fig. 7, the analysis of smart city at home and abroad is mostly from the perspective of the basic content, investment subject and implementation strategy of smart city, and more from the perspective of norms to sort out the "how to do" and "how to do" practice scheme. In other words, both academic and practical circles focus on whether the "leverage" role of smart city can be played, and focus on the cultivation role of smart city in social organization and social innovation, but fail to further explore other (potential) roles of smart city. At the same time, most of the studies related to Chinese scenes failed to break through the practice oriented "stereotype", and even failed to consider how to solve the problem of "replication" and "transformation" of new institutional forms into China. Therefore, although there has been a lot of practical experience, academic circles still fail to form a strong theoretical analysis model for the actual situation and subsequent evolution mechanism of smart city grafting into Chinese cities.

\subsection{Discussion}

Community is not only the basic unit of urban governance, but also the typical representative of urban community governance. Emergency makes the city face a lot of impact and great pressure. It is very important to build an effective community governance model for the sustainable development of the city. At present, international community governance community construction experience is relatively rich, while China's community governance community construction is still in its infancy, facing the problems of unreasonable space system design, insufficient financial policy support and inactive social network system. With the help of the theory of innovation ecosystem, this paper constructs the concept model of community governance and the urban community governance model including government service system, community self-organization system, intermediary auxiliary system and information exchange system. This new model can give full play to the self-organization function of 


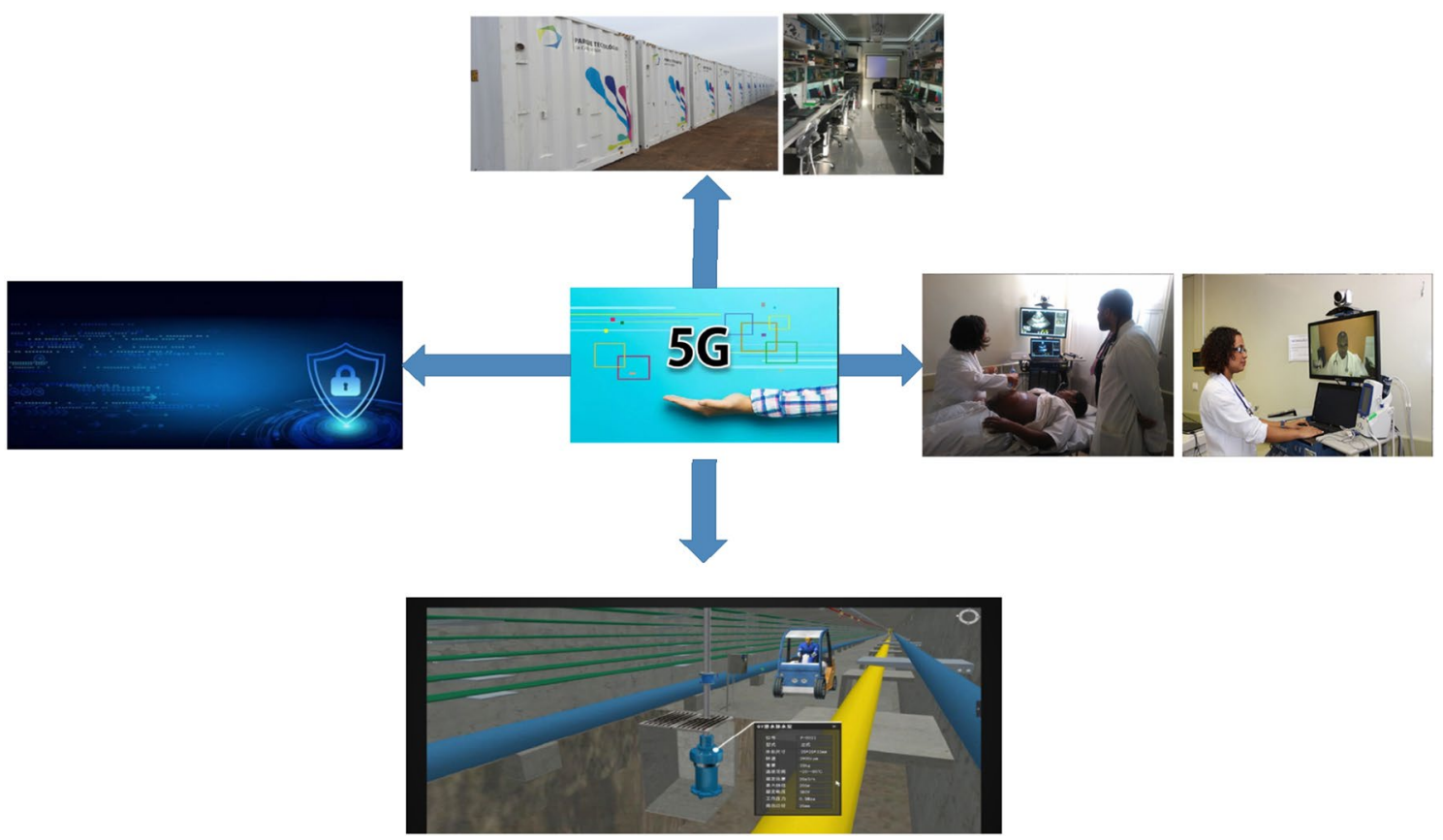

Fig. 7 The development direction of smart cities (Images retrieved from Google, none of the images have copyright requirements)

the community and the guiding role of the government, and multiple subjects participate in the community governance, community construction and governance. At the national strategic level, the government should promote the construction of community governance, promote the communication among community stakeholders, enhance the core competence of community assets, and promote the digitalization and intellectualization of the community.

With the development of globalization, human beings have entered the era of risk society. The living environment of residents is full of uncertain factors such as chronic pressure and acute impact. Community governance reflects the community's comprehensive ability to cope with external disasters, ecological environment deterioration, public health events and social and economic pressure, including the community's self-organization ability, pressure debugging ability, repair ability and adaptability.

\section{Conclusions}

The smart city community governance system based on online and offline aggregation services integrates the current fast communication system, image recognition algorithm and big data services. In the system of online and offline aggregation services, community governance has great advantages in industry, travel and transaction. Build the Internet of vehicles and Internet of things in the community, realize the application services such as collaborative driving, unmanned inspection and intelligent storage, and promote the construction of intelligent logistics. Build energy supply and demand collaborative optimization management system, real-time access to the use of each energy port in the community, record relevant historical information, and provide data support for community energy management. Based on the intelligent terminal of new technology, build intelligent operation management platform and community three-dimensional security system, reduce operation cost through digital management, and improve community safety monitoring and emergency response ability. Relying on advanced technology, integrating high-quality resources, establishing a sharing system, realizing the comprehensive coverage of services, promoting the integration of "four platforms of grassroots governance", and realizing digital lean management.

Author contributions XZ, CC: manuscript, Material preparation. YH: data collection and analysis.

Funding This work was supported by the major project of the Social Science Fund of Beijing (No.19ZDA05), and the Academic Research Projects of Beijing Union University (No.ZK120202103) and (No. ZB10202003).

\section{Declarations}

Conflict of interest The author(s) declared no potential conflicts of interest with respect to the research, author- ship, and/or publication of this article. 
Ethics approval This article does not contain any studies with animals performed by any of the authors. This article does not contain any studies with human participants or animals performed by any of the authors.

\section{References}

Battilana J, Leca B, Boxenbaum E (2020) How actors change institutions: towards a theory of institutional entrepreneurship. Acad Manag Ann 3(1):65-107

Bies A, Kennedy S (2019) The state and the state of the art on philanthropy in China. Int J Volunt Nonprofit Organ 30(65):619-633

Chen B, Sun H, Chen Y et al (2020) Energy circuit theory of integrated energy system analysis (I): gaseous circuit. Proc CSEE 40(2):436-443

Durand R, Rao H, Monin P (2020) Institutional change in Toque Ville: Nouvelle Cuisine as an identity movement in french gastronomy. Am J Sociol 108(4):795-843

Frumkin P (2020) Inside venture philanthropy. Society 40(4):7-15

Gao S, Chau KT, Liu C et al (2019) Integrated energy management of plug-in electric vehicles in power grid with renewables. IEEE Trans Veh Technol 63(7):3019-3027

Girardin L, Marechal F, Debuis M (2020) EnerGis: a geographical information based system for the evaluation of integrated energy conversion systems in urban areas. Energy 35(2):830-840

Graf S, Lanzerath F, Sapienza A et al (2019) Prediction of SCP and COP for adsorption heat pumps and chillers by combining the large-temperature-jump method and dynamic modeling. Appl Therm Eng 98(5):900-909

Greenwood R, Olive C, Thomas B (2008) The SAGE handbook of organizational institutionalism (2nd). SAGE 4(4):214-242

Haveman HA (2020) Hybrid forms and the evolution of thrifts. Am Behav Sci 49(7):974-986

Hsu CL (2020) Market ventures, moral logics, and ambiguity: crafting a new organizational form in post-socialist China. Sociol Q 47(1):69-92

Jing Y, Gong T (2020) Managed social innovation: the case of government-sponsored venture philanthropy in Shanghai. Aust J Public Adm 71(2):233-245

Letts CW, Ryan W, Grossman A (2020) Virtuous capital: what foundations can learn from venture capitalists. Harvard Bus Rev 75(2):36-38 (40-44)
Moody M (2020) "Building a Culture": the construction and evolution of venture philanthropy as a new organizational field. Nonprofit Volunt Sect Q 37(2):324-352

Onishi T (2019) Venture philanthropy and practice variations: the interplay of institutional logics and organizational identities. Nonprofit Volunt Sect Q 48(2):241-265

Shao C, Wang X, Wang X et al (2019) Probe into analysis and planning of multi-energy systems. Proc CSEE 36(14):3817-3829

Spires AJ (2018) Chinese youth and alternative narratives of volunteering. China Inf 32(2):203-223

Sun H, Guo Q, Zhang B et al (2018) Integrated energy management system: concept, design, and demonstration in China. IEEE Electrif Mag 6(2):42-50

Tracey P, Phillips N, Jarvis O (2020) Bridging institutional entrepreneurship and the creation of new organizational forms: a multilevel model. Organ Sci 22(1):60-80

Wang Y, Zhang N, Kang C (2019) Review and prospect of optimal planning and operation of energy hub in energy internet. Proc CSEE 35(22):5669-5681

Wu J, Yang Z, Wu Q et al (2012) Transient behavior and dynamic performance of cascade heat pump water heater with thermal storage system. Appl Energy 91(1):187-196

Xing L, Jiao B, Du Y et al (2020) Intelligent energy-saving supervision system of urban buildings based on the internet of things: a case study. IEEE Syst J 14(3):4252-4261

Xu X, Li K, Jia H et al (2018) Data-driven dynamic modeling of coupled thermal and electric outputs of microturbines. IEEE Trans Smart Grid 9(2):1387-1396

Zhou Y, Gu C, Wu H et al (2017) An equivalent model of gas networks for dynamic analysis of gas-electricity systems. IEEE Trans Power Syst 32(6):4255-4264

Zietsma C, Lawrence TB (2020) Institutional work in the transformation of an organizational field: the interplay of boundary work and practice work. Adm Sci Q 55(2):189-221

Publisher's Note Springer Nature remains neutral with regard to jurisdictional claims in published maps and institutional affiliations. 